\title{
Antimicrobial and antifungal activity of model drugs on the basis of food plant extracts in the systemic concept of health
}

\author{
Mykola Oseyko', Vasyl Shevchyk ${ }^{2}$, Olena Pokryshko ${ }^{3}$ \\ 1 - National University of Food Technologies, Kyiv, Ukraine \\ 2 - "Vasyl Shevchyk's eye microsurgery," Chernigiv, Ukraine \\ 3 - Ternopil State Medical University named after I. Ya. Grobachevsky, Ternopil, Ukraine
}

\section{Keywords: \\ Extract \\ Microorganism \\ Resistance \\ Drug \\ Microbiom}

Article history:

Received

20.01.2019

Received in

revised form

29.04.2019

Accepted

30.05.2019

\section{Corresponding author:}

Mykola Oseyko

E-mail:

nikios@ukr.net

\section{DOI:}

$10.24263 / 2310-$

1008-2019-7-1-9

\section{Abstract}

Introduction. We analyzed the antimicrobial and antifungal activity of samples of the preparation of KTIOL-BF on standard and resistant test strains of microorganisms. The aspects of microbiology and the systemic concept of health are considered.

Materials and methods. Strains of Gram-positive and Gramnegative microorganisms were used: S. aureus, S. saprophyticus, E. coli, P. aeruginosa, S. Epidermidis, and C. albicans fungi. Model drugs based on pyruvic extracts have been studied. The method of diffusion of substances into agar was used to determine the activity of drugs in relation to strains..

Results and discussion. The present state of physical, psychological and social existence of a person contributes to the accelerated proliferation of pathogenic microorganisms and the emergence of a resistant microflora. In recent years, almost everyone suffers from fungal diseases. The problem of health and healthy lifestyle is topical. Global is the problem of providing humanity with food.

Considered aspects of microbiome (endoecological aspectsT he importance of intestinal microbiota in human health and pathophysiology is indisputable.

Suggested the systemic concept of health (The systems KTIOL $^{\circledR}$ : 10 Basic Provisions for Prevention, Recovery, Treatment and Rehabilitation).

The tested microorganisms were sensitive to model specimens of the preparation KTIOL-BF (BF1-BF20). Samples of BF2, BF12, BF17 were found to be the most effective for the S. Saprophyticus test strain. It was found that the S. epidermidis test-microorganism was the most effective for the sample of the preparation BF34 (growth retardation zone was $30.40 \pm 1.29 \mathrm{~mm}$ ). The highest antifungal activity was found in samples of KTIOL-BF: BF33, BF37. Mushroom growth zones were respectively $20.76 \pm 1.65$ and $22.62 \pm$ $1.44 \mathrm{~mm}$.

The samples of the KTIOL-BF: BF-70, BF-87, BF-92 were shown to have a high inhibitory effect on clinical resistant strains of microorganisms. The diameter of the inhibition zone of resistant strains in KTIOL-BF87 was $22.17 \mathrm{~mm}$; the diameter of the PVI control sample was $13.05 \mathrm{~mm}$.

Conclusions. The raised antimicrobial and antifungal activity of KTIOL-BF preparations in relation to gram-positive and gramnegative microorganisms, $\mathrm{C}$. albicans fungi and resistant strains (PVI control) were revealed. 


\section{Introduction}

In the complex environmental and economic conditions of today, scientific and practical substantiation of the technologies of functional products, food supplements and preparations of gerontological and ophthalmologic direction is necessary [1,2,3]. At the same time, it is urgent to improve the concept of the endoecology of health as regards prevention, rehabilitation, treatment and rehabilitation of humans [4]. The present state of physical, psychological and social existence of a person contributes to the accelerated proliferation of pathogenic microorganisms and the emergence of a resistant microflora. This microflora interacts with human saprophytic microbes and can affect our physical health. Saprophytic microbes are trillions of microbes living on the surface and inside our body.

The review [5] substantiates the possibility of using plant products as antimicrobial agents. In recent years, the accelerated use and search of drugs and dietary supplements derived from plants. According to the author, it would be useful to standardize in vitro methods of extraction and testing for more systematic searching and ease of interpretation of results.

The study [6] confirmed the strengthening of the resistance of the microflora and drug strains to antibiotics and antiseptics, and, as a result, an increase in the incidence of secondary and postoperative infections.

The purpose of the study is to detect the antimicrobial and antifungal activity of the model specimens of the KTIOl-BF series and to present the basic provisions of the systemic health concept $\left(\mathrm{KTIOL}^{\circledR}\right.$ system).

Ten health problems affecting half the planet's population. The World Health Organization (WHO) experts have announced a five-year strategic plan [7] aimed at helping the three billion people without access to universal insurance and quality health services. As part of the project, WHO experts called the main threats to the health of the planet's population. In particular, the following 10 problems:

1. Air pollution. These air is breathing today 9 of 10 people;

2. Non-communicable diseases (diabetes, cancer or heart failure);

3. The danger of a global flu pandemic. Experts do not exclude that a large-scale epidemic can burst at any moment .;

4. Severe and life-threatening conditions (crises, wars, natural disasters, etc.) endanger the 1.6 billion people (almost $22 \%$ of the planet's population);

5. The growth of bacteria resistance to antibiotics does not allow to eradicate tuberculosis and other dangerous diseases;

6. Ebola fever has not yet been cured;

7. Serious threats to humanity are the poorly developed system of primary care, which is typical of many poor countries;

8. Negative people's attitude to immunization (according to WHO data, the number of cases of measles has grown by $30 \%$ recently);

9. Dengue infectious fever (up to 390 million infected per year);

10. Undefeated opponent - HIV.

Aspects of quality, safety and packaging of food and functional products. In today's social conditions, as before, the problem of health and healthy lifestyle is topical. After all, most people understand that products and preparations (biologically active ad ditives) should not only be tasty, but functional and safe.In particular, in Japan, the European Union, and the United States, especially in the context of public health, a healthy, creative and active lifestyle [8]. 
In the world one of the global concerns is the supply of humanity with food, which is connected with annual population growth and global warming of the climate, resulting in reduced areas of cultivated soils. It is important not only to find available sources of food supply but also to create such products that are safe and balanced by the chemical composition of nutrients $[8,9,10]$.

According to the data of the group of scientists on the problem of healthy eating [11] it is expedient to introduce in rations all categories of the population, the nutrients enriched with vital, food plants, seafood, etc.).

Innovative pharmacokinetic products, drugs based on medicinal and food plants and auxiliary active ingredients are presented in [1, 4, 9, 12].

In recent years, almost everyone suffers from fungal diseases, and these diseases are not treated with pharmacy drugs. Doctors recommend abandoning the modern (yeast) wi shop bread. The use of yeast bread can lead to various types of intoxication, fungal diseases, immune disorders, chronic and other diseases [13].

In study [14] methodology for testing natural compounds for determination of antifungal activity had been developed with adaptations. The most used are bioautography and agar diffusion with a complex and no defined media. In this study, different methods for determination of antifungal activity of natural products are discussed, and the use of M27A2 microdilution test from CLSI (Clinical and Laboratory Standards Institute, 2002), a methodology for testing plant extracts activity is recommended as a baseline.

The most common and dangerous defeat of the crumb of bread is potato disease. With the development of the disease, the breadcrumb acquires a hue of rotting fruit, etc. The disease is caused by the bacterium Bacillus subtilis - potato stick. Its spores are harmless, but at a temperature of about $40^{\circ} \mathrm{C}$, combined with humidity and low acidity, they develop into dangerous microbes.

White bread has a shelf life of not more than 24 hours after preparation. In rye bread, these bacteria do not multiply due to high acidity. The quality of baked bread should be monitored by manufacturers. It is advisable for buyers to purchase some bread and store them in "breathing" fabric bags in a cool place. Affected bread cannot be eaten categorically [15].

As a result of the systematic, integrated approach to the innovative technologies of bakery industries and new types of products with respect to their quality and safety $[16,17]$ developed the composition of polycomponent oxidants "Optical 1" and "Optical 2". Their influence on the length of the technological process, the influence of additives on the biochemical, microbiological, structural and mechanical properties of the dough and bread from the mixture of rye and wheat flour has been revealed. The new types of rye-wheat bread "Metropolitan Symphony" and "New Metropolitan Symphony" [18] were developed and introduced into the recipes and technological instructions on the basis of performed experimental research.

Microbiological studies of inhibitory action on some pathogens based on films with polyvinyl alcohol with nanoparticulate $\mathrm{TiO} 2$ powder are presented in [19]. It was found that the best method was to treat films of $\mathrm{TiO} 2(2.5 \%)$ with UV radiation. Solutions with $\mathrm{TiO} 2$ did not inhibit mushroom and yeast activity. TiO2 applied to the film inhibits the growth of bacteria (E. coli IEM-1, B. subtilis BT-2), growth retardation was not observed. Antimicrobial (TiO2) and other substances to enhance the nutritional value of products (vitamins C, F, fruit and vegetable powders, probiotics and elamine) should be used to provide the functional properties of biodegradable materials. A draft technical specification for food products has been developed. 
It is known that lactic acid bacteria (LABs) produce various antimicrobial compounds and play an important role in bioconservation of food and feed. LABs are of particular interest as a body of biosecurity [20].

In [21], on the basis of integrated feedbacks of wheat bread with edible coating and probiotic microorganisms, the improvement of bread quality was determined by organoleptic and microbiological parameters.

Thus, the protection of products in food technologies using a bioecological design in the form of high-quality and safe edible films or coatings is appropriate and relevant.The community of microorganisms formed during a person's life is a complex dynamic microecosystem whose change in composition can lead to illness of the oral cavity $[22,23]$.

The increasing clinical and microbiologic resistance of Candida spp. isolates to several antifungal agents are becoming a serious problem. It is now reasonable to propose the use of antifungal susceptibility testing in Candida spp. isolates from patients who have failed conventional therapy, before the selection of empirical therapy. The good diffusion test is simple, easy to reproduce, inexpensive, easy both to read and interpret and has a good correlation to the reference NCCLS microdilution test and may represent an alternative method for antifungal drug susceptibility testing of Candida spp., mainly in laboratories with few resources [24].

In [25]studed of antimicrobial and antifungal activity of different concentrations of the drug on the representative's oral microflora. It was concluded that the drug has antibacterial activity, and it is not selective. An increase in antimicrobial activity was observed with an increase in the concentration of the drug. Antifungal has indicated the effect of high concentrations of the drug.

The diverse collections of microorganisms associated with humans and other animals, collectively referred to as their "microbiome," are critical for host health, but the mechanisms that govern their assembly are poorly understood. This has made it difficult to identify consistent host factors that explain variation in microbiomes across hosts, despite large-scale sampling efforts. These results illustrate the importance of microbial dispersal to animal microbiomes and motivate its integration into the study of host-microbe systems [26].

Repair of tissue wounds is a fundamental process of restoring the integrity of tissues and regular function. It is important that infection is a major contributor to wound healing. Multicellular organisms have developed an arsenal of host defense molecules, including antimicrobial peptides (AMPs), aimed at controlling the proliferation of microbial organisms and modulating the host's immune response to a variety of biological or physical stroke. The role of AMR as endogenous wound healing mediators and their promising therapeutic potential for the treatment of skin-friendly skin and other epithelial injuries is showing [27].

According to the author's team [28], the importance of intestinal microbiota in human health and pathophysiology is indisputable. Despite the abundance of metagenomics data, the functional dynamics of gut microbiota in human health and disease remain elusive. Urolithin A (UroA), a major microbial metabolite derived from polyphenolics of berries and pomegranate fruits displays anti-inflammatory, anti-oxidative, and anti-ageing activities. Cumulatively, the results highlight how microbial metabolites provide two-pronged beneficial activities at gut epithelium by enhancing barrier functions and reducing inflammation to protect from colonic diseases.

Systemic concept of health (The systems KTIOL ${ }^{\circledR}$ : 10 Basic Provisions for Prevention, Recovery, Treatment, and Rehabilitation). The study of antimicrobial and antifungal model samples of drugs is based on the theory and practice of using KTIOL-I and KTIOL-II systems $[1,3,4,8,9,12]$. 
The preamble to the Charter of the WHO states that health is not only a lack of illness or physical defects but a state of complete physical, mental and social well-being. That is, health is the living conditions of the Personality when all organs fulfill their vital functions.

The system KTIOL-I (Comprehensive Technologies, Engineering, Equipment, Lines) was initially aimed at the synthesis of lipid-containing products of special purpose. Thus, based on the use of a systematic approach and analysis of identified problems, effective products, materials, drugs were created. In particular, for the oil and oil, petrochemical and metallurgical industries, the lipophilic substitute for palm oil K2, the lubricating and cooling technological equipment, technological and special mea $\mathrm{m}$ users correct twice as many mistakes as free users, on average: T6P, TVS, KTIOL-76, 77, 15. For the production of a range of special paste made of micron artificial diamonds and/or carbide - titanium fractions justified the use of hydrophilic - lipophilic systems based on oil, fatty, and substitutes of a number of $\mathrm{KTIOL}^{\circledR}$.

Basic principles of the system KTIOL-I are:

- providing the structure of the product (preparation) on the micro and nano levels;

- ecological and economic efficiency;

- a systematic approach to the methodology of safe food production, pharmaceutical and cosmetic products and drugs.

The system of KTIOL-II (Integrated therapy of individual health improvement) was started by analyzing indicators of quality and safety of water, food products, nutritional supplements and preparations, environmental and endoecological aspects of personal health.

The system KTIOL-II includes the following provisions (keywords and phrases):

A. Hygiene of thoughts. This is a positive, critical, rational thinking.

B. With Prevention. This is self-monitoring and periodic systemic examinations: ophthalmologic, dental, endoecological, electrocardiographic, gerontological, control of the body mass index, blood control for cholesterol, sugar, iodine, etc. It's time to spend time on your own health;

C. Water for health. Drinking water for consumption in a set of indicators should meet international standards of quality and safety. Drinking water of high quality should be specially prepared. The water that we constantly consume and in the required amount (approximately $30 \mathrm{ml}$ per $\mathrm{kg}$ body weight) should be a healing o-treatment. Quantity, conditions and time of consumption of good water are specified individually and seasonally. Good water has a positive effect on the quality of blood, on metabolic processes in the body and, accordingly, on the improvement of the health of the person;

D. Healthy eating. This is food therapy and a correct, individual gerontological balanced diet. Given the age, profession, state of the organism, active and creative life, nutrition in the realities of the present must be individually oriented: preventive, recreational, health-curative, medical and rehabilitation. Everyone should be identified and give up inappropriate food. It should also be remembered that vitamins that come from food are very important biological compounds for the normal functioning of all systems of the body.

In today's ecological and social conditions, people are beginning to think about the quality and safety of food in public and fast food establishments. In place of fast food, there are lay-foods - institute ions of leisurely wellness nutrition. It is known that the health or illness of a person depends, besides other factors, whether it eats the bacteria fermenting or rotting, and also consumes enough food with enough food fibers;

E. Healthy breathing.

F. Motion is life. More physical exercise in the wild should be used: walking, swimming, water excercises, active walks, Nordic walking, ball games, yoga exercises, etc. All these individual excercises contribute to the improvement of the organism and its 
immunity, especially in clear sunny weather. Keep track of your feelings, control your own pulse, the frequency of breathing, relax in time;

G. Microbial - is an individual, diverse collection of microorganisms in the body (preferably without their resistance). The microbial condition in the body is influenced by a healthy, active lifestyle, water, nutrition therapy, acid-base balance control, personal knowhow, etc.);

H. Massage. Massages are known to be used for daily activation of the body and prevention. In particular, morning (immediately after sleep), general, local, point (for example points E-36, GI-4, etc.), combined and special. Massages significantly contribute to strengthening the body's protective forces;

I. Individual know-how: personal and/or based on the use of the systemic health concept (KTIOL ${ }^{\circledR}$ system). This is the personal possession of tech, that is, knowledge, skill (skills, experience) and individual art with respect to its organism, self-control, selfperfection, and management of its own microbiome.

From the above provisions, we see that in addition to the hygiene of thoughts, systematic prevention, and improvement of the body, changes in nutrition and the influence of other factors, each person for the individual physical and mental well-being must have a high level of quality and safe microbial.

\section{Materials and methods}

\section{Materials to be explored}

Strains of Gram-positive and Gram-negative microorganisms were used: S. aureus (ATCC 6538), S. saprophyticus (ATCC 15305), E. coli (ATCC 25922), P. aeruginosa (ATCC 9027), S. Epidermidis and C. albicans fungi. The density of the microbial suspension was determined according to the standard of turbidity 0,5 by McFarland (equal to $1.5 \times 108$ colony-forming units ( $\mathrm{CFU}) / \mathrm{ml})$.

The study used samples of KTIOL-BF series. These functional and antioxidant drugs have been obtained on the basis of the systemic concept of health. The drugs of KTIOL-BF (biologically functional) series were used as model samples [4, 8].

Povidone-iodine, PVI (e.g., BETADINE, which is based on a solution of povidoneiodine, surface-active and auxiliary substances) were used as a control.

\section{Research order}

- Methodology analysis

- Preparation of exploratory strains of Gram-positive and Gram-negative microorganisms, model preparation of KTIOL-BF series and control drug

- Execution of planned research, processing and discussion of the results, conclusions.

\section{Evaluating research results}

According to the diameter of the microbial growth inhibition zone the following degrees of susceptibility to the antibacterial solutions were adopted:

- highly susceptible to drug sample - if the diameter of the growth inhibition zone of microorganisms exceeded $20 \mathrm{~mm}$;

- susceptible if the diameter was from 14 to $20 \mathrm{~mm}$;

- low susceptible - from 8 to $14 \mathrm{~mm}$.

All tests were performed triplicate, and average values were recorded. 
After the second layer of the agar was sealed, the cylinders were also removed in the formed wells; the samples of the investigational drugs were $0.3 \pm 0.03 \mathrm{ml}$. In one cup, Petri studied the activity of four or five different samples.

The seeds were incubated at $37^{\circ} \mathrm{C}$. for 48 hours. The results were determined in the presence of zones of growth retardation test-microorganisms, which were clearly visible around the walls.

By the degree of sensitivity of microorganisms to antibacterial solutions, we measured the diameter of the zone of suppression of microorganisms.

As a scientific and practical basis in the planning and implementation of this study, the systemic concept of health $[4,8]$ was used. This concept includes two systems of KTIOL.

\section{Antimicrobial activity screening of KTIOL-BF against Candida spp.}

The objects of study were KTIOL-BF numbered from 1 to 37 . The antimicrobial activity screening of KTIOL-BF against Candida spp. According to WHO recommendations the teststrain C. albicans ATCC 885-653 was used to investigate their antifungal effects.

In vitro studies were conducted using the wells method. Standardization of the substances diffusion into agar was provided using the thickness of nutrient media of $10 \mathrm{~mm}$ and the size of well $6 \mathrm{~mm}$. A suspension of the daily culture of the test microorganism was added at a concentration of $10^{7} \mathrm{CFU} / \mathrm{ml}$, which was determined by optical turbidity standard by McFarland. After inoculation of the test-strain onto the nutrient medium, the wells were filled with drops of BF. Further, Petri dishes were placed in an incubator at $37^{\circ} \mathrm{C}$. After 24 hours the results were registered by measuring the diameters of microbial growth inhibition around the well in millimeters. The evaluation of fungal susceptibility was performed according to the following criteria:

the absence of inhibition zone and zone up to $10 \mathrm{~mm}$ were evaluated as unsensitivity of C. albicans to KTIOL-BF;

- the inhibition zone from 11 to $15 \mathrm{~mm}$ - low sensitivity of test-strain to BF;

- the inhibition zone from 15 to $20 \mathrm{~mm}$ - sufficient sensitivity of test-strain to BF;

- the inhibition zone more then $20 \mathrm{~mm}$ - high sensitivity of test-strain to BF.

Povidon-iodine was used as a positive control.

The antifungal activity of each substance was checked out 10 times. Statistical analysis of the obtained results was carried out by the method of variation statistics.

\section{Results and discussion}

Taking into account the principles of the systemic concept of health and the physiologically functional system of KTIOL-II, samples of type KTIOL-BF $[4,8]$ included hydrophilic lipophilic extracts from plant and/or animal raw materials, antioxidants, biologically active and auxiliary components. The results of the study are presented in Tables $1,2,3$ and 4 . 
Research of model samples of KTIOL-BF (BF1-20)

Table 1

\begin{tabular}{|l|c|c|c|c|}
\hline \multirow{2}{*}{ KTIOL-BF } & \multicolumn{4}{|c|}{ Microorganisms / growth retardation zone, mm } \\
\cline { 2 - 5 } & Gram-positive microorganisms & Gram-negative microorganisms \\
\cline { 2 - 5 } & S. aureus & S. saprophyticus & E. coli & P. aeruginosa \\
\hline BF1 & $12,25 \pm 1,07$ & $16,81 \pm 1,08$ & $12,40 \pm 1,50$ & $12,63 \pm 1,71$ \\
\hline BF2 & $12,41 \pm 1,50$ & $20,25 \pm 1,16$ & $12,71 \pm 1,34$ & $13,45 \pm 1,57$ \\
\hline BF3 & $11,78 \pm 1,83$ & $16,57 \pm 1,80$ & $11,49 \pm 1,67$ & $11,86 \pm 1,92$ \\
\hline BF4 & $12,65 \pm 1,54$ & $12,24 \pm 1,64$ & $15,73 \pm 1,58$ & $14,58 \pm 1,34$ \\
\hline BF5 & $10,54 \pm 1,56$ & $14,12 \pm 1,73$ & $10,08 \pm 1,73$ & $13,44 \pm 1,39$ \\
\hline BF6 & $14,07 \pm 1,08$ & $18,46 \pm 1,24$ & $14,54 \pm 1,60$ & $14,46 \pm 1,68$ \\
\hline BF7 & $13,60 \pm 1,81$ & $16,58 \pm 1,75$ & $10,41 \pm 1,47$ & $12,18 \pm 1,81$ \\
\hline BF8 & $14,69 \pm 1,06$ & $16,47 \pm 1,24$ & $13,80 \pm 1,08$ & $14,72 \pm 1,08$ \\
\hline BF10 & $11,58 \pm 1,72$ & $11,51 \pm 1,45$ & $13,35 \pm 1,53$ & $12,54 \pm 1,37$ \\
\hline BF11 & $14,03 \pm 1,59$ & $13,72 \pm 1,87$ & $13,43 \pm 1,51$ & $12,67 \pm 1,65$ \\
\hline BF12 & $16,27 \pm 1,62$ & $20,49 \pm 1,39$ & $22,13 \pm 1,73$ & $20,43 \pm 1,60$ \\
\hline BF13 & $12,29 \pm 1,58$ & $13,36 \pm 1,56$ & $12,04 \pm 1,94$ & $11,86 \pm 1,53$ \\
\hline BF14 & $11,90 \pm 1,90$ & $13,80 \pm 1,09$ & $12,06 \pm 1,87$ & $11,74 \pm 1,76$ \\
\hline BF15 & $12,72 \pm 1,65$ & $11,71 \pm 1,63$ & $10,08 \pm 1,54$ & $13,40 \pm 1,35$ \\
\hline BF16 & $16,47 \pm 1,43$ & $15,76 \pm 1,69$ & $12,82 \pm 1,08$ & $14,87 \pm 1,25$ \\
\hline BF17 & $14,20 \pm 1,82$ & $20,47 \pm 1,23$ & $16,32 \pm 1,55$ & $12,48 \pm 1,70$ \\
\hline BF18 & $12,09 \pm 1,08$ & $15,41 \pm 1,83$ & $12,49 \pm 1,39$ & $12,28 \pm 1,64$ \\
\hline BF19 & $16,53 \pm 1,87$ & $17,56 \pm 1,62$ & $16,34 \pm 1,65$ & $18,36 \pm 1,52$ \\
\hline BF20 & $16,98 \pm 1,04$ & $15,71 \pm 1,09$ & $14,49 \pm 1,82$ & $12,46 \pm 1,09$ \\
\hline
\end{tabular}

Research of model samples of KTIOL-BF (BF 23-39)

Table 2

\begin{tabular}{|c|c|c|c|c|}
\hline \multirow{3}{*}{$\begin{array}{l}\text { KTIOL- } \\
\text { BF: }\end{array}$} & \multicolumn{4}{|c|}{ Microorganisms / growth retardation zone, $\mathbf{m m}$} \\
\hline & \multicolumn{2}{|c|}{ Gram-positive microorganisms } & \multicolumn{2}{|c|}{ Gram-negative microorganisms } \\
\hline & S. aureus & S. epidermidis & E. coli & P. aeruginosa \\
\hline BF23 & $\mid 16,56 \pm 1,28$ & $\mid 20,09 \pm 1,67$ & $14,72 \pm 1,54$ & $16,53 \pm 1,09$ \\
\hline BF24 & $12,80 \pm 1,52$ & $13,93 \pm 1,82$ & $14,56 \pm 1,20$ & $12,80 \pm 1,41$ \\
\hline BF25 & $18,27 \pm 1,71$ & $14,08 \pm 1,30$ & $16,49 \pm 1,85$ & 0 \\
\hline BF26 & $14,53 \pm 0,57$ & $15,42 \pm 1,43$ & $14,60 \pm 1,63$ & 0 \\
\hline BF27 & $16,39 \pm 1,71$ & $16,47 \pm 1,84$ & $13,82 \pm 1,67$ & 0 \\
\hline BF28 & $17,57 \pm 1,64$ & $18,09 \pm 1,41$ & $16,87 \pm 1,72$ & 0 \\
\hline BF29 & $18,45 \pm 1,60$ & $24,53 \pm 1,39$ & $14,81 \pm 1,40$ & $16,70 \pm 1,84$ \\
\hline BF30 & $15,71 \pm 1,79$ & $20,47 \pm 1,68$ & $12,49 \pm 1,71$ & $14,39 \pm 1,60$ \\
\hline BF31 & $14,70 \pm 1,36$ & $18,60 \pm 1,72$ & $11,62 \pm 1,83$ & $13,81 \pm 1,72$ \\
\hline BF32 & $18,37 \pm 1,59$ & $27,49 \pm 1,74$ & $16,83 \pm 1,80$ & $18,71 \pm 1,41$ \\
\hline BF33 & $14,40 \pm 1,73$ & $18,71 \pm 1,52$ & $17,29 \pm 1,73$ & $12,84 \pm 1,60$ \\
\hline BF34 & 0 & 0 & 0 & $30,40 \pm 1,29$ \\
\hline BF35 & $19,61 \pm 1,80$ & $20,58 \pm 1,40$ & $18,59 \pm 1,42$ & $18,61 \pm 1,67$ \\
\hline BF36 & $15,72 \pm 1,71$ & $14,55 \pm 1,60$ & $15,81 \pm 1,56$ & $12,73 \pm 1,34$ \\
\hline BF37 & $16,76 \pm 1,43$ & $20,70 \pm 1,32$ & $13,67 \pm 1,75$ & $12,55 \pm 1,39$ \\
\hline BF38 & $12,59 \pm 1,27$ & $16,72 \pm 1,38$ & $10,20 \pm 1,09$ & 0 \\
\hline BF39 & $14,82 \pm 1,67$ & $17,86 \pm 1,81$ & $12,57 \pm$ & $12,48 \pm 1,46$ \\
\hline BF40 & $12,80 \pm 1,52$ & $14,07 \pm 1,86$ & $11,50 \pm$ & 0 \\
\hline PVI & $11,86 \pm 1,39$ & $11,57 \pm 1,81$ & $\mathbf{0}$ & $\mathbf{0}$ \\
\hline
\end{tabular}


Table 3

Degree of susceptibility of the C. albicans ATSC 885-653 to the tested KTIOL-BFs

\begin{tabular}{|c|c|c|c|}
\hline $\mathbf{N}$ & KTIOL-BF: & Zone of growth inhibition, $\mathrm{mm}$ & $\begin{array}{l}\text { Degree of susceptibility of } \\
\text { C. albicans ATCC 885-653 }\end{array}$ \\
\hline 1 & BF1 & $12,12 \pm 1,09$ & low sensitivity \\
\hline 2 & BF2 & $12,14 \pm 1,34$ & low sensitivity \\
\hline 3 & BF3 & $14,07 \pm 1,53$ & low sensitivity \\
\hline 4 & BF5 & $12,05 \pm 1,56$ & low sensitivity \\
\hline 5 & BF6 & $13,45 \pm 1,72$ & low sensitivity \\
\hline 6 & BF7 & $14,06 \pm 1,64$ & low sensitivity \\
\hline 7 & BF8 & $16,05 \pm 1,52$ & sufficient sensitivity \\
\hline 8 & BF10 & $10,06 \pm 1,46$ & no sensitivity \\
\hline 9 & BF11 & $12,42 \pm 1,24$ & low sensitivity \\
\hline 10 & BF12 & $17,38 \pm 1,92$ & sufficient sensitivity \\
\hline 11 & BF13 & $10,08 \pm 1,48$ & no sensitivity \\
\hline 12 & BF14 & $12,24 \pm 1,32$ & low sensitivity \\
\hline 13 & BF15 & $9,84 \pm 1,89$ & no sensitivity \\
\hline 14 & BF16 & $14,24 \pm 1,43$ & low sensitivity \\
\hline 15 & BF17 & $13,83 \pm 1,08$ & low sensitivity \\
\hline 16 & BF18 & $12,05 \pm 1,59$ & low sensitivity \\
\hline 17 & BF19 & $15,82 \pm 1,44$ & sufficient sensitivity \\
\hline 18 & BF20 & $16,04 \pm 1,81$ & sufficient sensitivity \\
\hline 19 & BF23 & $12,65 \pm 0,98$ & low sensitivity \\
\hline 20 & BF24 & $18,42 \pm 1,59$ & sufficient sensitivity \\
\hline 21 & $\mathrm{BF} 25$ & $15,93 \pm 1,57$ & sufficient sensitivity \\
\hline 22 & BF26 & $11,83 \pm 1,28$ & low sensitivity \\
\hline 23 & BF27 & $16,07 \pm 1,52$ & sufficient sensitivity \\
\hline 24 & BF28 & $15,75 \pm 1,46$ & low sensitivity \\
\hline 25 & BF29 & $17,61 \pm 1,88$ & sufficient sensitivity \\
\hline 26 & BF30 & $16,64 \pm 1,34$ & sufficient sensitivity \\
\hline 27 & BF31 & $13,72 \pm 1,08$ & low sensitivity \\
\hline 28 & BF32 & $18,04 \pm 1,43$ & sufficient sensitivity \\
\hline 29 & BF33 & $20,76 \pm 1,65$ & sufficient sensitivity \\
\hline 30 & BF34 & 0 & no sensitivity \\
\hline 31 & BF35 & $18,29 \pm 1,37$ & sufficient sensitivity \\
\hline 32 & BF36 & $15,82 \pm 1,72$ & low sensitivity \\
\hline 33 & BF37 & $22,62 \pm 1,44$ & sufficient sensitivity \\
\hline 34 & BF38 & $17,31 \pm 1,90$ & sufficient sensitivity \\
\hline 35 & BF39 & $17,55 \pm 1,31$ & sufficient sensitivity \\
\hline 36 & BF40 & $17,09 \pm 1,69$ & sufficient sensitivity \\
\hline 37 & PVI & $14,02 \pm 1,87$ & low sensitivity \\
\hline
\end{tabular}


Testing of KTIOL-BF specimens on clinical polyresistant strains

\begin{tabular}{|c|c|c|c|c|c|c|c|}
\hline KTIOL-BFN & E. coli & P.aeruginosa & S. aureus 5 & S. aureus 6 & S. aureus 5 & Citrobacter & \\
\hline & 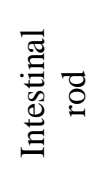 & 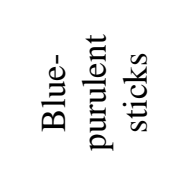 & 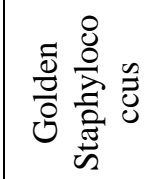 & 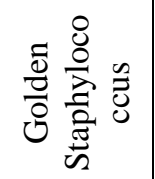 & 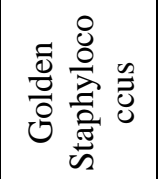 & 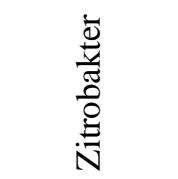 & 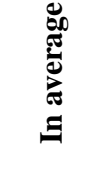 \\
\hline BF70 & 24 & 18 & 18 & 22 & 20 & 20 & 20,3 \\
\hline BF82 & 14 & 18 & 10 & 18 & 12 & 14 & 14,33 \\
\hline BF83 & 14 & 16 & 10 & 12 & 0 & 14 & 11 \\
\hline BF87 & 26 & 20 & 21 & 20 & 22 & 24 & 22,17 \\
\hline BF88 & 18 & 0 & 16 & 15 & 16 & - & 13 \\
\hline BF89 & 20 & 16 & 13 & 12 & 14 & 20 & 15,83 \\
\hline BF92 & 24 & 16 & 20 & 22 & 22 & 20 & 20,67 \\
\hline BF93 & 22 & 16 & 14 & 18 & 18 & 14 & 17 \\
\hline BF98 & 18 & 18 & 24 & 16 & 18 & 16 & 18,33 \\
\hline BF99 & 22 & 22 & 22 & 18 & 16 & 16 & 19,33 \\
\hline \multirow[t]{3}{*}{ PVI } & 12 & 10 & 14 & 18 & 12 & 12 & \\
\hline & 14 & 10 & 12 & 15 & 10 & 10 & \\
\hline & 12 & 10 & 20 & 18 & 12 & 14 & \\
\hline $\begin{array}{l}\text { In } \\
\text { average: } \\
\text { PVI }\end{array}$ & 12,66 & 10 & 15,33 & 17 & 11,33 & 12 & 13,05 \\
\hline
\end{tabular}

As shown in the results obtained (Table 1), the samples of the KTIOL-BF sample tested with the antimicrobial activity of different strength were relatively promising test microorganisms.

Samples of the KTIOL-BF (BF1-BF20) to which test-microorganisms were susceptible were detected. Samples of BF2, BF12, BF17 were found to be the most effective for the S. Saprophyticus test strain. The growth retardation zones of $\mathrm{S}$. saprophyticus were respectively $20.25 \pm 1.16,20.49 \pm 1.39$ and $20.47 \pm 1.23 \mathrm{~mm}$.

Based on the results of the analysis of Table 2 data, samples of KTIOL-BF (BF23BF39) showed the antimicrobial activity of varying strength in relation to the proposed test microorganisms.

The test strain of S. epidermidis was insensitive to only 2 drugs: BF24, BF34. It was found that the $\mathrm{S}$. epidermidis test-microorganism was the most effective for the sample of the preparation BF34 (growth retardation zone was $30.40 \pm 1.29 \mathrm{~mm}$ ). But to other test strains, this sample was inert.

Good antimicrobial activity among others was demonstrated by BF32 and BF35. The PVI control test was low-susceptible to gram-positive and non-susceptible to gram negative test microorganisms.

The KTIOL-BF (BF1-BF39 specimens) have also been shown to have antimicrobial activity in relation to the $\mathrm{C}$. Albicans ATCC 885-653 microbial test strain (Table 3). The test strain was insensitive to only 4 KTIOL-BF specimens (BF10, BF13, BF15, BF34). The C. albicans anti-yeast fungi were KTIOL-BF samples: BF8, BF12, BF17, BF19, BF24, BF28, 
BF29, BF30, BF32, BF35, BF37. The inhibition zones of fungal growth were 13,25 $\pm 1,19$ $\mathrm{mm}$ on average. The highest antifungal activity was found in samples of KTIOL-BF: BF33, BF37. Mushroom growth zones were respectively $20.76 \pm 1.65$ and $22.62 \pm 1.44 \mathrm{~mm}$. Test strain C. Albicans ATCC 885-653 was sensitive to 5\% of PVI (Povidone-iodine) in the lowgrade $-12.09 \pm 1.92 \mathrm{~mm}$.

According to Table 4, according to the diameters of the inhibition zone of resistant strains of microorganisms, the following is observed.

Samples of KTIOL-BF: BF-82, BF-89, BF-93, BF-98, BF-99 were sufficiently susceptible to the diameter of the inhibition zone of growth of microorganisms. The high susceptibility of resistant strains to samples of KTIOL-BF: BF-70, BF-87, BF-92 was revealed. The best sample of KTIOL-BF87 $(22.17 \mathrm{~mm})$ was the best in the largest diameter of the inhibition zone of resistant strains of microorganisms from the three samples of KTIOL-BF (BF-70, BF-87, BF-92).

The average diameter of the zone of inhibition of growth of microorganisms in the control sample PVI was $13.05 \mathrm{~mm}$, that is, the inhibition of growth of microorganisms was low in susceptibility.

time the possibility of high antimicrobial action of samples of the preparation of KTIOL-BF32 and38 on the E. coli strain $(30 \mathrm{~mm}$ growth retardation diameter) was confirmed.

It was found that samples of the KTIOL-BF model preparations compared with the control agents (BETADINE /PVI, Chlorophyllipt) showed higher and good antimicrobial pro perties for S. Aureus, S. Saprophyticus, E. coli, P. Aeruginosa, and integral strains.

The obtained data confirmed the expediency of further in- depth studies of antimicrobial and antifungal activity of hydrophilic and/or lipophilic drugs of a number of KTIOL in the systemic concept of health, in particular in the treatment of ophthalmic and gerontological prophylaxis, treatment and rehabilitation.

\section{Conclusions}

On the basis of analytical and experimental research, new data on the antimicrobial properties of samples of model preparations of KTIOL-BF on the basis of two-phase extracts from animal and plant raw materials were obtained.

For the first time, the possibility of high antimicrobial action of samples of the preparation of KTIOL-BF32 and38 on the E. coli strain (30 mm growth retardation diameter) was confirmed.

It was found that samples of the KTIOL-BF model preparations compared with the control agents (BETADINE /PVI, Chlorophyllipt) showed higher and good antimicrobial pro perties for S. Aureus, S. Saprophyticus, E. coli, P. Aeruginosa, and integral strains.

The obtained data confirmed the expediency of further in- depth studies of antimicrobial and antifungal activity of hydrophilic and/or lipophilic drugs of a number of KTIOL in the systemic concept of health, in particular in the treatment of ophthalmic and gerontological prophylaxis, treatment and rehabilitation. 


\section{References}

1. Oseyko M.I. (2008), Gerodiyetichni produkty, BAD i geroprotektory v sisteme KTIOL, Molochnaya promyshlennost', 3, pp. 51-56.

2. Nikberg I.I. (2011), Functional foods in the structure of modern power, International Journal of Endocrinology, 6(38).

3. Oseiko N.I., Shevchyk V.I (2015), Gerontological aspects of prevention of ophthalmic diseases in the system KTIOL II, Pharmacology, Pharmaceutical Technology and Pharmacotherapy in Active Longevity: a book of abstracts of the II International Scientific Conference, OIHN, Vilnius, 60, p. 46.

4. Mykola Oseiko, Vasyl Shevchyk, Tetiana Romanovska (2017), Functional products and preparations in the systemic concept of health, Ukrainian Food Journal, 6(4), p. 661-673.

5. Cowan M.M., (1999), Plant products as antimicrobial agents, Clin.Microbiol. Rev., 12:564-582.

6. Willy Chin, Guansheng Zhong, Qinqin Pu (2018), A macromolecular approach to eradicating multidrug-resistant bacterial infections while mitigating drug resistance onset, Nature Communications, 9, Article number: 917.

7. WHO has named the main threats to the health of people affecting half the planet's population (2019), Available at https://politeka.net/zdorovye/880575-voz-nazvala-glavnye-ugrozyzdorovju-ljudej-v-opasnosti-3-milliarda/ 20.01.2019.

8. Oseyko M., Romanovska T., Shevchyk V. (2017), Funktsional'nyy produkt v kontseptsiyi endoekolohiyi zdorov"ya (Functional products in endoecology health concepts), Scientific Works of NUFT, 23(3), p. 192-203.

9. Oseyko N.I. (2006), Tekhnolohiia roslynnykh olii, Varta, Kyiv.

10. Romanovska T.I. (2006), Fizyko-khimichni aspekty kharchovykh tekhnolohiy, Naukova dumka, Kyiv.

11. Tutel'yan V.A., Vyalkov A.I., Razumov A.N., et ai. (2010), Nauchnye osnovy zdorovogo pitaniya, Panorama, Moscow.

12. Mykola Oseyko, Vasyl Shevchyk, Olena Pokryshko (2018), Antimicrobial properties of model drugs in the systemic concept of health, Ukrainian Food Journal, 7(3), p. 434-442.

13. Magazinnyy drozhzhevoy khleb nanosit vred zdorov'yu (2018), Sudebno-yuridicheskaya gazeta / Store yeast bread harms the health (2018), Judicial and Legal Newspaper, 12-14 (431-433) April 9, Available at https://sud.ua/ru/news/obshchestvo/117277-chem-opasen-khleb-iz-magazinavrac h-obyasnil

14. The use of the standard methodology for determination of antifungal activity of natural products against medical yeasts candida sp and cryptococcus sp. (2007), Liliana Scorzoni,Tatiane Benaducci, et al., Brazilian Journal of Microbiology 38, pp. 391-397.

15. Kogda khleb stanovitsya opasnym dlya zdorov'ya / When bread becomes hazardous to health (2019), Available at: https://ukrhealth.net/mediki-poyasnili-koli-xlib-staye-nebezpechnim-dlyazdorovya45754/

16. Syl'chuk T.A. Drobot V.I. Antonyuk M. (2005), Obrobka zhytn'o-pshenychnoho khliba, Khlibopekars'ka i kondyters'ka promyslovist', 1, pp. 3-5.

17. Drobot V.I., Hryshchenko A.M., Syl'chuk T.A. (2016), Innovatsiyni tekhnolohiyi diyetychnykh ta ozdorovchykh khlibobulochnykh vyrobiv: monohrafiya, Kondor, Kyiv.

18. Sylchuk T., Bilyk O., Kovbasa V., Zuiko V. (2017), Investigation of the effect of multicomponent acidulants on the preservation of freshness and aroma of rye-wheat bread, Eastern-european journal of enterprise technologies, 5/11(89), pp. 4-9.

19. Anastasiya Chorna, Oksana Shulga, Larisa Arsenieva et al., (2016), Antibacterial biodegradable films for foods, Ukrainian Food Journal, 5(1), pp. 88-95.

20. Messens, W., De Vuyst, L. (2002), Inhibitory substances produced by Lactobacilli isolated from sourdoughs - a review, Int. J. Food Microbiol., 72, pp. 31-43.

21. Chernaya A.I., Shul'ga O.S., Arsen'yeva L.Yu. (2017), Otsenka organolepticheskikh i mikrobiologicheskikh pokazateley kachestva pshenichnogo khleba so s"yedobnym pokrytiyem, soderzhashchim probioticheskiye mikroorganizmy (2017), Voprosy pitaniya, 86(3), pp. 101-107. 


\section{- Food Technology}

22. Borovskiy Ye.V., Mashkilleyson A.L. (2001), Zabolevaniya slizistoy obolochki polosti rta i gub, Medpress, Moscow.

23. Gracheva I.V., Yepisheva A.A. (1999), Mesto i rol' gribov roda Candida v klinike krasnogo ploskogo lishaya, Dostizheniya, nereshennyye problemy i perspektivy razvitiya stomatologii na Urale, Materialy itogovoy nauchno-prakticheskoy konferentsii, pp. 65-66.

24. Well diffusion for antifungal susceptibility testing (2004), Magaldi S, Mata-Essayag S, Hartung de Capriles C, et al., Int J. Infect Dis., 8(1), pp. 39-45.

25. Protopopova T.A., Porseva J.D., Lunitsyna J.V., et al., (2013), The antimicrobial properties of the drug based on the extract Grapefruit seed (experimental study) Dentistry problem, 2, pp. 42 45 .

26. Adam R. Burns, Elizabeth Miller, Meghna Agarwa (2017), Interhost dispersal alters microbiome assembly and can overwhelm host innate immunity in an experimental zebrafish model, PNAS published ahead of print, Available at https://doi.org/10.1073/pnas.1702511114

27. Maria Luisa Mangoni, Alison M. McDermott, Michael Zasloff (2016), Antimicrobial peptides and wound healing: biological, and therapeutic considerations, Experimental Dermatology, 25(3), Available at: https://doi.org/10.1111/exd.12929.

28. Rajbir Singh, Sandeep Chandrashekharappa, Sobha R. Bodduluri (2019), Enhancement of the gut barrier integrity by a microbial metabolite through the Nrf2 pathway, Nature Communications, 10, Article number: 89. 